\title{
O DESENVOLVIMENTO HUMANO NA ALTERIDADE DOCENTE: A QUESTÃO DA LINGUAGEM E OS MEIOS DIGITAIS
}

\author{
Deysi Maia Clair Kosvoski* \\ Sara Farias da Silva
}

\begin{abstract}
RESUMO: Este estudo versa sobre a linguagem utilizada na formação humana em processos educativos, tem por objetivo refletir sobre a relação entre linguagem e formação humana em meios digitais, a partir de como as relações intersubjetivas podem apresentar dois aspectos: se forem de alteridade, por meio da linguagem, podem afetar o outro em sua singularidade e fazê-lo sentir-se acolhido e reconhecido, ou em segundo aspecto, o outro ao perceber-se tolerado e assim excluído, sentir-se negado. A discussão é orientada pela análise de conteúdo em pesquisa exploratória bibliográfica à luz do pensamento teórico dos autores Nadja Hermann, Mikhail Bakhtin, Ricardo Hack, principalmente. Em diálogo com esses autores, foram realizados levantamentos dos conceitos, oriundos e circulantes pela Educação a distância - EaD. Ao final deste estudo, foi averiguado a maneira como uma perspectiva dialógica pode contribuir com o contexto $\mathrm{EaD}$, principalmente no que se refere à linguagem no desenvolvimento formativo humano.
\end{abstract}

PALAVRAS-CHAVE: Linguagem; Formação humana; Alteridade; Tecnologias digitais; Educação a distância.

\section{Introdução}

A educação na conjuntura da dimensão capitalistas e o crescente número de cursos e níveis de formação à distância, considerando os formatos das relações dialógicas próprias dessa modalidade, são fatores pontuais para se observar as intersubjetivações - relações

\footnotetext{
* Mestranda em Educação (Unoesc). Especialista em Linguagens e Educação a Distância (Ufsc). Professora da Fundação Catarinense de Educação Especial (FCEE).

${ }^{* *}$ Doutora em Linguística pela Universidade Federal de Santa Catarina (Ufsc). Professora da Ufsc. Pesquisadora convidada na Universidade de Montréal (UDEM).
} 
entre as subjetividades - necessárias ao desenvolvimento humano. As sensibilidades dos envolvidos nos processos de aprendizagem quanto a escolha do discurso, contribuem com a construção de relações dialógicas que estabelece vínculos de acolhimento, cooperação e compreensão do ‘outro’ - sujeito interlocutor -. Esses aspectos são os suportes necessários ao convívio social e possibilitam, além do crescimento formativo, teórico, técnico e prático, o crescimento subjetivo do sujeito. A 'alteridade' - principalmente, reconhecimento em aceitação do outro -, manifestada por intermédio do uso de uma linguagem sensível, é recebida pelo outro de forma a fazê-lo, oras modificar-se, oras completar-se, conforme a compreensão e aceitação no momento da recepção da mensagem. O sujeito, docente ou discente, ao proferir suas palavras direcionadas ao outro, atinge-o em sua 'singularidade' relacionada a elementos subjetivos ou traços característicos da forma física, natural, cognitivas e psicológicas do desenvolvimento humano -, e esse atingir o outro, pode variar conforme a intenção do locutor com a recepção de suas palavras pelo interlocutor.

Em contra ponto às relações de alteridade, alguns fatores apresentam responsabilidade pela mecanização da sensibilidade, ou seja, o não se importar com o outro, resultado da fragmentação da subjetividade do ser humano em formação. A falta dessas relações dialógicas com alteridade nos processos educacionais é favorecida pelo contexto da racionalidade capitalista, motivadora da corrida humana para alcançar o avanço tecnológico, bens materiais e posição social, em detrimento do avanço ético e moral, da humanidade em si. Esta maneira de viver e de educar-se, faz fragmentar a subjetividade do ser humano em formação. Essa fragmentação - divide a subjetividade em partes - e freia o desenvolvimento da dimensão humana nos sujeitos, desenvolve a dimensão individualista, marcada pelo exigente eficientismo econômico neoliberal. Esse eficientismo quer o sujeito polivalente, ou seja, aquele que consegue realizar o maior número de funções, e o faz por meio da competição pelo prêmio, pela conquista do cargo, pelo consumo e pelo status social, pelo melhor perfil nas redes sociais, dentre outros fatores. O individualismo caracterizado como um "empresariamento de si" - sujeito em busca de méritos pessoais para ascender em um sistema de hierarquização -, se constitui na negação do outro, quando o sujeito se 
eleva acima das relações intersubjetivas, dialógicas e de alteridade, para inflar o ego, sobressaindo-se aos demais, e inconscientemente, isso faz do próprio sujeito o seu algoz, pois, o torna incapaz de olhar para o outro e o ver como seu semelhante, de sentir suas dores, de se compadecer de seus problemas e de lhe estender as mãos em socorro em prol do bem comum, por isso, interfere em seu desenvolvimento formativo humano.

Os aspectos da dimensão formativa humana relacionada às formas de melhorar o desenvolvimento dos alunos em processos educativos por intermédio dos meios tecnológicos, nos move em direção as reflexões pertinentes às relações de alteridade por intermédio da linguagem. Compreendemos a educação a distância como um dos meios pelo qual acontece a formação humana. Da mesma forma que proporciona um encontro relacional dos sujeitos/alunos com ideais semelhantes, a educação a distância em ambiente tecnológico digital os reúne.

O encontro relacional nos processos educativos ocorre em diálogo e, este é considerado constitutivo da língua como prática social, assim a complexidade do papel educador desse diálogo, consiste em conduzi-lo de forma ética, sensível e respeitoso. A linguagem neste estudo se configura uma prática formativa nos relacionamentos intersubjetivos que acontecem nos processos de aprendizagem por intermédio das tecnologias digitais. Acreditamos que se esses relacionamentos dialógicos forem em alteridade - ou seja, que ao dialogar com seu interlocutor - professor, aluno ou tutor, possa existir abertura ao que vem do outro, respeito e aceitação às singularidades -, geram aproximações dos estudantes, por suas humanidades, envolvendo-os em significantes aprendizagens. Nesse sentido, este estudo traz como objetivo a reflexão sobre como a linguagem pode afetar o outro em sua singularidade, ou seja, a sensibilidade no trato com o outro pode fazer com que este se sinta acolhido e sua aprendizagem ocorra animosamente; ou, diferentemente, o outro pode se sentir negado por se perceber tolerado - visto que "tolerar" é suportar sem aceitar de fato -, ao ponto de renunciar ao curso.

Para esse estudo são trazidos ao diálogo, principalmente, as contribuições de Nadja Hermann, com as obras “Autocriação e Horizonte Comum (2010)" e "Ética e Educação: 
outra sensibilidade (2014)"; e também de Mikhail Bakthin, no campo da Linguística da Enunciação, na obra "Marxismo e Filosofia da Linguagem (1997)". Seja sob a assinatura de Bakhtin, Bakhtin/Voloshinov ou Medvedev, trata-se de desenvolver perspectivas enunciativas da linguagem, nas quais se encontra a descrição de alteridade, por meio da discussão sobre a concepção dialógica da linguagem (o discurso, a enunciação e a palavra). Em sua obra "Estética da Criação Verbal (1997)", Bakhtin apresenta a estética como uma criação artística e ética, conforme as interpretações das obras de Dostoievski e de Rabelais; além disso, o autor aborda, a relação dialógica do autor com o herói a partir do campo "interacional” (BAKHTIN, 1997b). Para a contextualização com a EaD o autor Josias Ricardo Hack faz reflexões em suas obras "Introdução à Educação a Distância (2011)" e a "Afetividade na Educação a Distância (2016)", sobre conceitos que corroboram com Bakhtin e Hermann.

Dessa forma, apresentamos os conceitos que nos movem em direção da formação humana com práticas docentes que envolvam relações dialógicas de alteridade e, para tanto, apresentamos as definições provenientes dos estudos a partir dos autores referenciados.

\section{O sujeito}

O ser humano se constitui ‘sujeito’ na linguagem e por meio da linguagem porque só a linguagem fundamenta sua consciência de se fazer humano. A consciência de si mesmo acontece mediante a presença do outro. Assim, a existência do 'eu’ sugere um diálogo experienciado, em que cada locutor apareça como sujeito. Os sujeitos em interação verbal empreendem um processo ativo e responsivo em torno do diálogo, porém os sujeitos são passíveis de discordâncias e podem, também, apresentar dificuldades em relacionamentos estabelecidos em grupos de aprendizagens.

O sujeito, para Bakhtin, é aquele “enunciador ou interlocutor" ativamente compreensivo na atividade dialógica do processo de comunicação, em que a resposta que vem do outro, opera como algo novo. Cabe mencionar que Bakhtin realiza um paralelo em seus estudos literários: trata da novela polifônica e do principal para nosso estudo, o diálogo 
interno fundante da própria personalidade, as denominadas ‘linguagens sociais', representadas pela linguagem dos sujeitos. O diálogo interno é culturalmente engendrado e cada voz representa uma posição distinta, considerando a bagagem cultural da sociedade em que os sujeitos estão inseridos. A educação a distância reúne sujeitos de diferentes culturas e suas formas de se expressar podem ser entendidas como pacíficas ou conflituosas, devendo ser mediadas pelo professor-tutor - é o primeiro contato do estudante com a instituição e serve de guia em todos os processos, desde a matrícula, condução da vida acadêmica e demais instâncias. O professor-tutor ajuda o estudante a se adaptar a comunidade universitária virtual e interage com os alunos pela internet, via Campus Virtual - Entretanto, a dificuldade consiste na mediação de um conflito em um curso à distância, pois a mediação é um método pacífico de resolução de conflito pelo qual o tutor é o responsável por alcançar o diálogo cooperativo entre as partes. Nesse sentido, acreditamos que desenvolver relações dialógicas consensuais em meio digital de educação a distância, ou e-learning, traz a colaboração, a cooperação, o diálogo vivo e construtivo e a permanência dos alunos até o final do curso.

A questão do ‘outro’ discutida como ‘sujeito’ para Bakhtin (1997a, 1997b) e Hermann $(2005,2010,2014)$ se apresenta como importante aspecto para o presente estudo, pois envolve conceitos fundamentais de suas teorias, como linguagem, dialogismo, estética, alteridade e ideologia. Enquanto Hermann (2010) nos diz que, etimologicamente, o termo 'outro' provém do grego 'to etepov' e do latim 'alteritas', e costuma ser empregado como equivalente à alteridade, o que significa constituir-se como outro; para Bakhtin (1997b), o sujeito e a linguagem do eu-outro travam uma relação de interdependência: língua e sujeito em relações dialógicas que se constituem em dinâmicas sociais, ou seja, o sujeito é constituído socialmente a partir da interação verbal na relação com o outro.

O sujeito é também o 'outro', como é a si mesmo, constituído socialmente a partir da interação verbal na relação intersubjetiva. O 'outro' é um aspecto de identificação e diferenciação. Por conseguinte, o outro é o ser que se apresenta face a face, com sua dife- 
rença e estranhamento, heterogêneo em relação ao outro, como tudo que pertence à consciência. É por meio de outro que proferimos o nosso discurso e nos desestabilizamos em confronto, aceitação, recusa e negação, associado ao inquietante, ao não familiar (HERMANN, 2014, p. 480; BAKTHIN, 1997a, p. 45). Para Bakhtin, é nas relações dialógicas que se constituem as ideologias, as lutas de classe, conforme revela seu viés marxista. No entanto, Bakhtin parece concordar com Hermann no quesito das relações dialógicas filosoficamente se constituírem em relações sociais de alteridade.

\section{Relações dialógicas}

Bakhtin (1997b; 1997a) explica a conexão entre os sujeitos, em suas obras como relações dialógicas ou interrelações sociais e ideológicas, onde os sujeitos ocupam na existência um lugar concreto e singular. Hack (2016) contextualiza o pensamento bakhtiniano para a realidade da educação a distância como "ato educativo e afetivo que é um ato eminentemente dialógico que requer respeito e entrega" (HACK, 2016, p. 133). Hack descreve, ainda, a relação intersubjetiva em relação com a alteridade, quando escreve "ato dialógico, respeito, entrega". Compreendo respeito em alteridade e entrega como aceitação e abertura ao outro.

As relações de alteridade, ou sejam, relações as quais os interlocutores utilizam uma linguagem respeitosa, que propõe abertura ao diálogo; requerem responsabilidade sobre a enunciação, já que envolvem o interlocutor e sua capacidade responsiva. Lembramos aqui o entendimento de Bakhtin sobre "sujeito" ativamente compreensivo da atividade dialógica, do processo de comunicação, de modo a considerar a resposta que vem do outro como algo novo. A alteridade necessita da compreensão do sujeito na atividade dialógica ao responsabilizar-se pelo o interlocutor e ouvir seu discurso, isto, em face da abertura ao outro, a predisposição em aceitar o outro e a responsabilidade com a receptividade das palavras no outro.

Segundo Hack (2011), na comunicação educativa a distância se estabelece um processo comunicacional entre os envolvidos, na construção do conhecimento, por meio de 
reflexões sobre as tecnologias disponíveis e sobre a comunicação dialógica. Segundo o autor (2011, p. 47), “deve ser a base do processo de ensino aprendizagem em um sistema de $\mathrm{EaD}$ que pretende promover a emancipação dos estudantes”. A comunicação dialógica referida por Hack pode ser entendida em termos do dialogismo de Bakthin e das relações de alteridade e estéticas defendidas por Hermann.

No que tange a educação à distância, a relação de alteridade se manifesta como um desafio à interação entre professores, alunos e tutores. Fomentar colaboração e cooperação à distância, por meio das mídias em ambientes virtuais de aprendizagem, não é algo fácil. As Tecnologias da Informação e Comunicação - TIC -, utilizadas para abrigar o "Modular Object-Oriented Dynamic Learning Environment" - MOODLE -, no Ambiente Virtual de Aprendizagem - AVA -, sem dúvida, contemplam as ideias pedagógicas contemporâneas. Entretanto, essa mesma contemporaneidade vem sendo marcada pela busca pela eficiência, fruto do pensamento econômico neoliberal, através da competição que se constitui na negação do outro.

A enunciação como base da língua possui sua realidade sócio-ideológica e pode ir além do discurso exterior, incluindo o discurso interior ou o discurso consigo mesmo. Para Bakhtin, signo e situação social são intrinsecamente unidos, já que todo signo é ideológico. Nesse sentido, a consciência, cuja atividade mental do sujeito é acomodada pela língua e formatada pela ideologia sofre intersubjetivações, ou melhor dizendo, sofre inter-relações de comando. Desta forma, o monólogo na enunciação, surge entre o psiquismo e a ideologia, em uma espécie de constante interação dialética no subjetivismo individualista.

O outro se constitui socialmente por meio de suas interações e de seus diálogos (BAKHTIN, 1997a, 1997b), o que requer além do respeito e da entrega, o acolhimento do “outro" (HERMANN, 2010), especialmente em uma modalidade de estudo que envolve uma maior dedicação de todos os envolvidos, bem mais que o ensino presencial. Para Hack (2016, p. 133), “os interactantes apenas conseguirão, verdadeiramente, alcançar-se mutua- 
mente se houver um movimento recíproco de busca por compreender o outro", por "fundir-se com ele" (BAKTHIN, 1997a, p. 45). A interação e a linguagem se tornam as bases do processo de aprendizagem.

Para Bakhtin, a fala é a máquina responsável por transformações semânticas, com a palavra, os sujeitos entram em conflito ou consenso, pois qualquer linguajar é repleto de valores sociais e culturais, além de diferenças sociais. A comunicação verbal, inseparável das outras formas de comunicação, implica conflitos, relações de dominação e de resistência, adaptação ou resistência à hierarquia, além da utilização da língua pela classe dominante para reforçar seu poder etc.

\section{Intersubjetividade e sociedade}

A experiência da intersubjetividade, refere-se a uma concepção de ser humano que integra em sua constituição a experiência da alteridade. A intersubjetividade, em suma, significa a capacidade singular de elaboração psíquica de leitura de aspectos sensíveis, crenças, sentimentos, intenções e processos mentais de outros sujeitos. No que se refere à sociedade, para Bakhtin (1997b, p. 95), “a palavra está sempre carregada de um conteúdo ou de um sentido ideológico ou vivencial”, enquanto para Hermann (2010, p. 103) "a sociedade supõe uma compreensão de bem comum, de um mínimo de acordos sobre regras que viabilizam a vida social, cultural e política, da qual estamos afastados pela fragmentação".

Martin Buber (1878-1965) desenvolve com profundidade reflexiva a relação ontológica 'eu-tu', em que a palavra se apresenta como dialógica; no entanto, a dialogicidade da palavra é o 'entre', eu e tu, a interrelação, ou seja, a interação das subjetividades. As subjetividades estão sempre em formação, considerando a capacidade de cada sujeitos em se relacionar com os outros. Mas existe aquele que não se relaciona, que prefere não criar pontes. Em Totalidade e Infinito, para Levinas a subjetividade é calcada na separação, em que a

separação é o próprio acto da individuação, a possibilidade, de uma maneira geral, para uma entidade que se põe no ser, de nele se pôr 
não definindo-se pelas referências a um todo, pelo seu lugar num sistema, mas a partir de si. (LEVINAS, 2000, p. 279)

Esta separação ou preferência de fazer sozinho, o mal chamado 'individualismo', se faz presente também na EaD. Transforma o ser humano e o fragmenta, dividindo-o, e com isso, o faz esquecer das relações intersubjetivas, afetando negativamente seu desenvolvimento humano. Esse é um panorama político-educacional da qual emerge a reflexão sobre a falta de reconhecimento do outro, e da necessidade da sensibilidade estética e da alteridade.

O pensamento de Lévinas sobre a intersubjetividade na obra "Entre Nós” (LEVINAS, 2005) se depara com a realidade urgente do caos que enfrenta a humanidade, pela falta de reconhecimento do outro com alteridade, causa provável de tragédias, conflitos violentos e da necessidade de uma educação para a paz.

Para Bakhtin (1997a, p. 170), este individualismo demonstra o desejo de ser herói na vida, de ter importância no mundo dos outros, de atingir a glória. Para ele, nós temos dentro de nós um herói biográfico, com atos e valores estéticos próprios que podem operar como valores que organizam a representação artística do autor. Bakhtin (idem) diz que esses são valores de natureza individualista, embora se trate

de um individualismo ingênuo, que não se isola do mundo dos outros e participa da alteridade existencial de que necessita e de cuja autoridade ele extrai sua própria força (o eu-para-mim solitário não se opõe ao outro enquanto tal, como no caso da confissão marcada de antropomaquia). Esse individualismo ingênuo e espontâneo se correlaciona com um funcionamento parasitário ingênuo, espontâneo. (BAKHTIN, 1997a, p. 170)

A preocupação com o individualismo do personagem herói, com alteridade e o contexto das relações na EaD, nos fazem refletir filosoficamente no que Bakhtin chama de "o eu-para-mim solitário não se opõe ao outro enquanto tal [...]”. Nesse caso, não se percebe o outro, nem acontece o estranhamento, pois como diz Hermann (2010, p. 131), "a estética tem se mostrado hábil na experiência de alteridade, evidenciando aquilo que é estranho, 
uma liberdade do sensível contra o embrutecimento da percepção automatizada”, mas ainda não atingiu muitos sujeitos que ainda estão no 'eu-para-mim'. A realidade aligeirada, quase totalmente automatizada, em que vivemos, indica a necessidade da alteridade e da criação de um 'mundo comum', de uma sociedade mais justa, sem a traiçoeira ingenuidade individualista.

De acordo com Hermann (2010, p. 103), “a sociedade supõe uma compreensão de bem comum, de um mínimo de acordos sobre regras que viabilizam a vida social, cultural e política, da qual estamos afastados pela fragmentação". Sem alteridade em um mundo comum a educação se fragmenta ao preço altíssimo da desorientação. Para Hermann, (2010, p. 106) “educar é uma forma de vida que requer elaborações incompatíveis com o aceleramento do tempo virtual proporcionado pelas novas tecnologias, embora possamos nos valer dele". Assim, se faz necessário demorar-se sobre a realidade do estudo, contemplar, pensar, fazer pontes entre os conhecimentos e interpretações hermenêuticas. Hermann aponta para a sensibilidade docente em olhar para a subjetividade do aluno, com uma compreensão mais aberta às relações de alteridade.

A alteridade não é tão simples, mas ao mesmo tempo se torna simples na análise da complexidade filosófica com a qual se aproximam os pensamentos de Bakhtin e Hermann. Bakhtin (1997a) faz reflexões filosóficas ao realizar interpretações hermenêuticas das obras literárias de Dostoievski e de Rabelais. O autor age com empatia e realiza a experiência da autocriação com a profundidade com a qual direciona suas análises, a exemplo de sua obra 'Estética da criação verbal'. Bakhtin assim se refere ao princípio da alteridade:

o simples fato de eu conceder um significado, se bem que infinitamente negativo, ao que me determina, e de questioná-lo, ou seja, de eu tomar consciência de mim mesmo na existência, esse simples fato atesta que não estou sozinho em minha introspecção-confissão que meus valores são refratados em alguém, que há alguém para quem apresento interesse, que há alguém que necessita que eu seja bom. (BAKHTIN, 1997a, p. 159)

Pela alteridade, a tomada de consciência explicada por Bakhtin, se faz necessária ao ocorrer a elaboração interna do espírito humanístico, sendo que o princípio da alteridade é 
transcendente à autoconsciência e implica o reconhecimento do outro por mim e reciprocamente pelo outro em dialogismo (BAKHTIN, 1997a; HERMANN, 2010).

\section{Linguagem}

A responsabilidade para com as palavras verbalizadas é uma grande preocupação ética-filosófica de Bakhtin (1997b), que valoriza a questão da linguagem-enunciado, em uma relação intrínseca com as situações sociais. A linguagem é no sentido mais amplo, um fenômeno ideológico (BAKHTIN, 1997b) e o modo mais puro e sensível de relação social. Por meio da manifestação da linguagem verbal o sujeito chega à interação social e, ao enunciar, o sujeito invoca valores, reinventa sentido, contribui com a expressão, o tom e o desejo discursivo. Todos os valores socioculturais e ético-morais da constituição do sujeito trazidos em seu discurso se referem à estética.

Bakhtin (1997a), ao se posicionar entre o autor e herói, realiza interpretações estéticas, observa as intenções mais profundas do autor, levando em conta aspectos imbricados na idealização e constituição de um ser ‘herói’. A estética aprofundada no diálogo dos personagens para além das palavras, foi alvo de discussões éticas e estéticas em reuniões de Bakhtin com amigos intelectuais no chamado 'Círculo de Bakhtin'. As considerações estético-formais, discutidas no encontro do círculo, são estabelecidas pelo reconhecimento, das singularidades, do contexto social, histórico e cultural.

As observações críticas, éticas e estéticas que Bakhtin faz às obras refletem a alteridade, pois a linguagem filosófica, se aprofunda nas subjetividades de cada personagem, de forma a reconhece-las ou negá-las, chegando ao herói como uma necessidade do autor. Esse exemplo protagoniza o sujeito da educação a distância.

O herói, para a EaD, seria aquele que se sobressai, que faz o empresariamento de si, que toma conta da sua carreira e estuda além do que conseguiria, se a educação fosse presencial. Este é um dos discursos do sujeito antenado, competente com o uso das tecnologias, mas que precisa constantemente lembrar do humano em si, para se relacionar com 
o humano do outro. Desta forma, o reconhecimento da singularidade do outro e o estabelecimento de uma relação dialógica consensual "com-sentir" contempla o acolhimento do outro.

Para Bakhtin (1997b, p. 95), o acolher acontece pela palavra, visto que, "a palavra está sempre carregada de um conteúdo ou de um sentido ideológico ou vivencial". Por meio da palavra pode-se formar relações de alteridade e construir subjetividades, pois os relacionamentos acontecem entre duas ou mais pessoas, assim a palavra se constitui como o produto da interação do locutor e do ouvinte e, segundo Bakhtin, toda palavra serve

de expressão a um em relação ao outro. Através da palavra, definome em relação ao outro, isto é, em última análise, em relação à coletividade. A palavra é uma espécie de ponte lançada entre mim e os outros. Se ela se apoia sobre mim numa extremidade, na outra apoiase sobre o meu interlocutor. (BAKHTIN, 1997b, p. 113)

Atentar para como se proferem as palavras. torna-se uma ponte para a alteridade. Hermann (2010) também cita que é pela linguagem falada (tom de voz, intensidade), corpórea (postura) e visual que os sentidos repercutem no outro. Nadja Hermann, em seu diálogo por cartas (eletrônicas 'e-mails') com Marcia Tiburi, em Diálogo/Educação, explica a estética da seguinte forma:

A estética se relaciona com nossa capacidade de apreender a realidade pelos canais da sensibilidade e põe em movimento uma disposição lúdica para a atividade criadora [...] remete ao, sensível, que envolve todo o sujeito e traz uma profunda inserção na totalidade da vida. (HERMANN, 2014, p. 85)

Trata-se de construção de sentido pela sensibilidade e pela linguagem, e isso se inicia pela palavra, como diz a obra de Bakhtin "Dialogismo, o princípio dialógico constitutivo da linguagem e de todo discurso" (BRAIT, 2005). Para Bakhtin, a linguagem tem uma ligação com a vida, pois a língua é dialógica e complexa e não se pode ignorar essa natureza. Nesse sentido, Hermann nos diz que é na relação com o outro, pela linguagem, sendo assim também chamada de dialógica, que as relações de alteridade acontecem pela sensibilidade 
de percepção do outro. Tendo feita essa explanação teórica sobre os conceitos de sujeito, intersubjetividade, relações dialógicas e estética - na sua relação com a linguagem -, a seguir apresento reflexões sobre a EaD.

\section{Educação a distância}

A história da EaD se relaciona à evolução humana, em um primeiro momento há um interesse ou necessidade em comunicar-se com alguém distante, em que se pode notar a preocupação com o outro. Em um segundo momento, tem-se a ideia do ensino por correspondência, por preocupação com o outro, por faltar às aulas, ou por falta prevista do professor ou, ainda, por motivo de doença; nesses casos, a matéria era enviada ao lar. Depois, seguiu a percepção de uma forma empreendedora lucrativa, através da venda de cursos/aulas por correspondência.

Data de 1728, o primeiro vestígio de educação a distância, quando o professor Caleb Phillips publicou na Gazeta de Boston um anúncio dizendo que poderia enviar aulas para as casas de quem desejasse, todas as semanas. Em 1833, na Suécia, Lunds Weckoblad enviou remessas postais aos que estudam "Composição” por correspondência. Outros anúncios semelhantes ocorreram na Inglaterra em 1840. Essas demandas geraram transformações nas sociedades, na cultura dos povos e na educação mundial.

A primeira instituição de educação a distância, legalizada para o envio de correspondência, na modalidade ensino, data de 1856, em Berlim, com os professores Charles Toussain e Gustav Laugenschied, que ensinavam Francês. Depois, as Universidades assumiram esse papel, como: Wisconsin (1891), Chicago (1892) e Oxford (1895), que inseriram a certificação da educação a distância, por correspondência. Após a primeira guerra a União Soviética, implementou um sistema de educação a distância, o qual chegou a atender aproximadamente 350 mil pessoas.

Na sequência dos fatos, com a necessidade de levantar a autoestima da população no pós-guerra e profissionalizá-la, a educação a distância passou a ter suas aulas transmitidas via rádio, sendo este o primeiro recurso tecnológico utilizado na educação a distância. 
Foi disseminada mundialmente e logo banalizada, tendo diminuído a audiência, provocado novas formas de educação a distância, para atingir sempre um maior número de pessoas.

No Brasil, as primeiras iniciativas de EaD surgiram no início do século XX, com o ensino técnico por correspondência, seguidas pelo rádio. Até o início dos anos 1990, não foi constatado que instituições de ensino superior se utilizassem dessa modalidade para o ensino. Contudo, a educação a distância avançou tecnologicamente: teve gravações em fitas cassete, transmissão por televisão, sempre com material escrito impresso. Com a evolução temporal, outras tecnologias foram incorporadas a $\mathrm{EaD}$, como o computador com internet e, atualmente, os multimeios e a educação corporativa e-learning.

De acordo com Hack (2011, p. 49), “o desenvolvimento das mídias modificou o sentido de pertencimento dos indivíduos, pois eles passaram a ser cosmopolitas, ou seja, cidadãos do mundo", não importando suas localizações. As iniciativas educacionais no Brasil passaram por estágios de humanização, enfocando a educação para aqueles que não tiveram condições de ingressar no ensino superior. Assim foi a EaD, contudo, as aulas eram após o trabalho, no chão de fábrica arranjado como sala de aula.

Promessas de seguir carreira na empresa incentivaram o estudo EaD, caracterizando um empresariamento de si. Para Bakhtin (1997a, p. 170), este individualismo demonstra o desejo de ser herói na vida, de ter importância no mundo dos outros, de atingir a glória. Bakhtin cita que "o eu-para-mim solitário não se opõe ao outro enquanto tal [...]". Nesse contexto, não se percebe o outro, nem acontece o estranhamento, pois, como diz, Hermann (2010, p. 131), “a estética tem se mostrado hábil na experiência de alteridade, evidenciando aquilo que é estranho, uma liberdade do sensível contra o embrutecimento da percepção automatizada", Acredito que a $\mathrm{EaD}$, nessa visão empresarial, atingiu muitos sujeitos, pois está focada no 'eu-para-mim'; deste modo, as opiniões convergem para um individualismo competitivo, compondo o perfil do sujeito que participa da EaD.

\section{Análises}

Ao refletir sobre os fatos históricos ocorridos no contexto do início da $\mathrm{EaD}$, podese perceber que a educação teve um caráter de dominação ideológica, como um modo de 
direcionar os sujeitos para determinada informação. Tendo em vista o contexto políticosocial no qual se instalou a educação a distância, as ideias de Bakhtin e Hermann nos ajudam a compreender a intenção do sentido da palavra (signo) direcionado ao bem comum.

A sociedade com a evolução tecnológica tem se preocupado pouco com o ser humano e, quando revolucionam inserindo o termo 'interação', não se refere aos seres humanos, mas sim à interatividade elevando os meios tecnológicos. A falta de atenção com a interação dos sujeitos nos documentos legais da Educação, causa a fragmentação das subjetividades pelo fato de tornar menos importante as relações humanas; por consequência a prevalência de barbáries.

As relações dialógicas quando com alteridade são responsáveis, ou seja, compreensivas e abertas à responsividade com aceitação do que vem do outro, e, uma vez direcionadas para o sucesso da aprendizagem em ambientes virtuais se constituem de educação dialógica e dependem do professor/tutor e de sua condução do fluxo de diálogo, mantido por meio de sua linguagem.

De acordo com os estudos e levantamentos documentais e bibliográficos, foi possível chegar às considerações de que as relações dialógicas, de sensibilidade estética e de alteridade não estão presentes na história da EaD. O que há refere-se à “efetiva interação e complementariedade entre a presencialidade e a virtualidade "real". o local e o global, a subjetividade e a participação democrática nos processos ensino e aprendizagem". Isso nos parece um pedido de colaboração entre educação presencial e virtual, porém, quando citam subjetividade, se referem ao sujeito aluno ou professor. A partir da contextualização surgem as reflexões sobre como a linguagem pode afetar o outro em sua singularidade. Bakhtin e Hermann nos respondem que os sujeitos são afetados pela linguagem e que se faz necessário o entendimento da alteridade. 


\section{Considerações finais}

Diante do aumento significativo da oferta de todos os níveis de formação na modalidade EaD, o avanço desenvolvimentista das Tecnologias da Informação e Comunicação - TIC -, sem dúvida, contempla as ideias demandas contemporâneas.

A corrida humana para alcançar o avanço tecnológico, contudo, fragmenta o ser humano, marcado pelo exigente "eficientismo" econômico neoliberal que o quer polivalente, e o faz por meio da competição, como, por exemplo, pelo prêmio, pela conquista do cargo, dentre outros. O "empresariamento" de si se constitui na negação do outro, quando o sujeito se eleva acima das relações intersubjetivas, dialógicas e de alteridade, para inflar o ego, sobressaindo-se aos demais.

A compreensão sobre este contexto da $\mathrm{EaD}$ fez com que este estudo sobre as relações dialógicas em processos de aprendizagem em meio de interação digital fosse visto como necessário para a formação profissional, extrapolando a formação teórica, técnica e prática, em busca de uma formação da dimensão humana, da humanização dos sujeitos.

A partir dos estudos e análises, os fenômenos evidenciaram vestígios de que a discussão sobre como se mostrar sensível pela linguagem, é necessária em um curso a distância. Dialogamos com autores que trazem em seu discurso não só a sensibilidade com as palavras, mas a responsabilidade pelo discurso, pela enunciação e proferimento.

Pela linguagem o ser humano se faz humano, se percebe sujeito autor de seu diálogo interno e capaz de afetar o outro em sua singularidade. Compreendemos que cada sujeito, aluno(a) da EaD ao ingressar no curso, traz consigo sua cultura, sua singularidade, sua subjetividade e linguajares próprios. De acordo com os autores estudados, somente por intermédio da alteridade se pode fazer com que se sintam acolhidos e motivados a aprender.

Um curso EaD não se faz de atores, mas de educadores capazes de ver através do meio digital quem é o(a) aluno(a) distante. Utilizar os recursos tecnológicos como tecnologia assistiva e encará-la como ferramenta, considerar o humano e as relações humanas, não 
apenas sua habilidade técnica de acesso e manuseio do curso, nos mostra ser algo imprescindível e urgente.

A formação via EaD é referência como educação ao longo da vida, segundo o documento vigente de Incheon e, por isso, a nossa grande preocupação com as relações dialógicas de alteridade, pois, enquanto responsáveis pelas relações humanas, os educadores formarão os sujeitos que serão o futuro; e os sujeitos do futuro precisarão ser mais humanos do que já fomos, precisarão evitar guerras, fome e genocídios.

As relações dialógicas quando consensuais são responsáveis, ou seja, compreensivas e abertas à responsividade com aceitação do que vem do outro, e, uma vez direcionadas para o sucesso da aprendizagem em ambientes virtuais se constituem de educação dialógica e dependem do tutor e de sua condução do fluxo de diálogo, mantido por meio de sua linguagem.

De acordo com os estudos e levantamentos documentais e bibliográficos, vimos que não há menção sobre a preocupação com o humano no percurso histórico da educação a distância. Foi possível chegar às considerações de que as relações dialógicas, de sensibilidade estética e de alteridade não estão presentes na história e nem nos documentos legais da EaD. O que há refere-se à "efetiva interação e complementariedade entre a presencialidade e a virtualidade "real". o local e o global, a subjetividade e a participação democrática nos processos ensino e aprendizagem". Isso nos parece um pedido de colaboração entre educação presencial e virtual, porém, quando citam subjetividade, se referem ao sujeito aluno ou professor.

A partir da contextualização surgem as reflexões sobre como a linguagem pode afetar o outro em sua singularidade. Bakhtin e Hermann nos respondem que os sujeitos são afetados pela linguagem e que se faz necessário o entendimento da alteridade.

Geralmente os cursos EaD iniciam com fórum de apresentações e aula sobre a história da EaD, sendo assim, sugere-se que se traga o humano para a história da EaD: quem era o sujeito, o que sentia, como era seu contexto social, político e cultural, dentre outras questões. Então, após isto, sugerimos um tópico de estudo sobre relações dialógicas de 
alteridade. Destaca-se que esses fatores relacionados acima podem ajudar a humanizar os cursos EaD de forma que os sujeitos/alunos possam se sentir acolhidos e concluam com êxito seus cursos.

\title{
HUMAN DEVELOPMENT IN THE TEACHING OTHERNESS: THE LANGUAGE AND DIGITAL MEDIA PROBLEM
}

\begin{abstract}
This study deals with the language used in human formation in educational processes, aims to reflect on the relationship between language and human formation in digital media, from how intersubjective relations can present two aspects: if they are of alterity, through the language, may affect the other in their uniqueness and make him feel welcomed and acknowledged, or secondly, the other in feeling tolerated and thus excluded, feeling denied. The discussion is guided by content analysis in exploratory bibliographic research in light of the theoretical thinking of the authors Nadja Hermann, Mikhail Bakhtin, Ricardo Hack, mainly. In dialogue with these authors, surveys of the concepts, originating and circulating through distance education - distance education were performed. At the end of this study, it was investigated how a dialogical perspective can contribute to the distance education context, especially with regard to language in human formative development.
\end{abstract}

KEYWORDS: Language; Human formation; Alterity; Digital technologies; Distance education.

\section{REFERÊNCIAS}

BAKHTIN, M. Estética da criação verbal. Tradução feita a partir do francês por Maria Emsantina Galvão G. Pereira revisão da tradução Marina Appenzellerl. — 2’ cd. São Paulo: Martins Fontes, 1997a.

- Marxismo e Filosofia da Linguagem: problemas fundamentais do Método Sociológico na Ciência da Linguagem [tradução de Lahud e Vieira]. São Paulo: Hucitec, $1997 b$.

BARDIN, L. Análise de conteúdo. Lisboa: Edições 70, 2010.

BRAIT, B (org.). Bakhtin, dialogismo e construção do sentido. Campinas, SP: Editora da Unicamp, 2005.

BUBER, Martin. Eu e Tu. São Paulo: Centauro, 2001.

HACK, J. R. Gestão da educação a distância. Indaial: ASSELVI, 2009.

. Introdução à educação a distância. Florianópolis: LLV/CCE/UFSC, 2011. 
.; ALBUQUERQUE, D. A. Afetividade na Educação a Distância: um estudo de caso sobre o curso de Letras-Português na modalidade a distância da UFSC. Revista Educação e Linguagens, v. 5, p. 132-149, 2016.

HERMANN, N. Hermenêutica e Educação. Coleção [o que você precisa saber sobre...] Rio de Janeiro: DP \& A.2002.

2010.

- Autocriação e Horizonte Comum: ensaios sobre educação ético-estética. Ijuí: Unijuí,

- A questão do outro e o diálogo. Revista Brasileira de Educação,

v. 19, no 57, p. 477-493, abr./jun. 2014a. Disponível em: http://www.scielo.br/ pdf/rbedu/v19n57/v19n57a11.pdf. Acesso em: 5 jul. 2019.

. Ética e Educação: outra sensibilidade. Belo Horizonte: Autêntica, 2014b.

LÉVINAS, E. Totalidade e Infinito. Lisboa, Edições 70, 2000.

. Entre nós: ensaios sobre a alteridade. 2. ed. Petrópolis: Vozes, 2005.

MOORE, M.; KEARSLEY, G. Educação a distância: uma visão integrada. São Paulo: Cengage Learning, 2007.

SILVA, M. EAD on-line, cibercultura e interatividade. In: ALVES, L.; NOVA, C. (Org.). Educação a distância: uma nova concepção de aprendizado e interatividade. São Paulo: Futura, 2003.

TIBURI, M.; HERMANN, N. Diálogo/Educação. São Paulo: Senac São Paulo, 2014.

Recebido em: 31/08/2019.

Aprovado em: 20/01/2020. 